\title{
COVID-19 and Portuguese Adults with Intellectual Disabilities
}

\author{
Cristina P. Albuquerque*
}

\begin{abstract}
University of Coimbra, Center for Research in Neuropsychology and Cognitive and Behavioural Intervention, Faculty of Psychology and Educational Sciences, Rua do Colégio Novo, 3000-115 Coimbra, Portugal
\end{abstract}

\begin{abstract}
The COVID-19 pandemic has changed the lives of people all over the world, including in Portugal. This study explores the impact of the pandemic on several life domains of Portuguese adults with Intellectual Disabilities (ID) and their families; identifies the difficulty level in the implementation of the most common preventive measures by adults with ID; addresses the consequences of health authorities' guidelines in the activities carried out in daycare centers for people with disabilities. A total of thirty-three daycare centers participated; they were attended by a total of 1192 adults at the time the study took place (between the $15^{\text {th }}$ of September 2020 and the $15^{\text {th }}$ of October 2020), and a professional belonging to the daycare center answered an online survey. The results showed that: 1) participants agreed that the pandemic had a negative impact on adults with ID and their families, although only in a percentage of them; 2) in the cases of the adults and families where that negative impact occurred, it was generalized, expressing itself in various life domains; 3) almost all of the preventive measures where considered difficult to apply by adults with ID; 4) the participants agreed that the health authorities' guidelines influenced the activities that were performed in the daycare centers, i.e., there were less activities, and the existing ones were less diversified, more sedentary and occurring indoors more often. The implications of the negative impact of the pandemic on adults with ID, their families, and the services provided have to be addressed.
\end{abstract}

Keywords: COVID-19, impact, adults with Intellectual Disabilities, families, preventive measures, daycare centers.

The COVID-19 pandemic has changed the lives of people all over the world. Portugal is no exception both in terms of infected people and lost lives and in terms of restrictions to daily living, including isolation and lockdown.

The first lockdown period in Portugal lasted two months (from the $13^{\text {th }}$ of March 2020 until the $18^{\text {th }}$ of May 2020) and entailed the closing of schools, trade, childcare centers, and daycare facilities for older people and people with disabilities. The subsequent gradual reopening of some services and facilities has been discontinued by the summer holidays in July and August 2020. Service infrastructure restarted in September 2020 and was in place until the end of 2020. A second lockdown period happened at the beginning of 2021 and lasted almost three months (from the $15^{\text {th }}$ of January 2021 until the $5^{\text {th }}$ of April 2021).

The consequences of these long confinement periods intersected with periods of marked restrictions to daily life (the "new normal") are important for everyone. However, the impact has been assumed to be even greater for people with disabilities, including people with Intellectual Disabilities (ID) and their families and caretakers. A possible negative impact upon the mental health of people with ID has been

*Address correspondence to this author at the University of Coimbra, Center for Research in Neuropsychology and Cognitive and Behavioural Intervention, Faculty of Psychology and Educational Sciences, Rua do Colégio Novo, 3000115 Coimbra, Portugal; Tel: 239851 450; Fax: 239851 462;

E-mail: calbuquerque@fpce.uc.pt advanced [1, 2] and even observed by recent research [3-5]. The burden on families and caregivers of people with disabilities has also been considered particularly heightened due to, for instance, the withdrawal of community-based supports [6], and mental health problems on caregivers have already been reported [7].

Nevertheless, empirical research regarding Portuguese adults with ID is lacking: the impact of COVID-19 on the lives of adults with ID may extend to life domains, other than mental health, such as physical health, cognitive functioning, interpersonal relationships (including family relationships), basic daily activities or finances. A similar hypothesis can also be considered regarding the families of people with ID.

Another important question that has also been raised $[1,8,9]$ concerns the challenges and difficulties that people with ID might have complying with preventive measures (e.g., using a mask properly, keeping a distance of two meters from other people, avoiding sharing objects). Although these measures are mandatory in many countries, we do not know which ones are followed with more or less difficulty by people with ID.

When the services for people with ID are open and functioning, they also have to guarantee the adoption of preventive measures and comply with the health authorities' guidelines. In Portugal, one of the main facilities for adults with ID are daycare centers, originally named Centers of Occupational Activities $(\mathrm{COA})$ and recently renamed Centers of Activities and 
Empowerment for Inclusion [10]. These centers are attended by adults with disabilities, aged 18 or more, who cannot have a professional activity. Since the COVID-19 pandemic, they must follow strict functioning rules, such as favoring individual activities, implementing activities in shifts, or frequent sanitization of equipment. However, the consequences of these rules in the activities performed in the COA are unknown.

Therefore, the aims of this paper are: to explore the impact of the pandemic on several life domains of adults with ID and their families; to identify the difficulty level in the implementation of the most common preventive measures by adults with ID; to understand the consequences of health authorities' guidelines in the activities that are now carried out in the COA. We will focus on adults with ID that attended COA and in the period between the $15^{\text {th }}$ of September 2020 and the $15^{\text {th }}$ of October 2020 , that is, after the first lockdown and the summer holidays.

\section{METHOD}

\section{Participants}

The COA were contacted by email through the address and emailing lists of two large associations for people with ID (FENACERCl; Humanitas) and of a public rehabilitation organization (Instituto Nacional de Reabilitação). Sixty COA were contacted, given information about the study, and asked to participate. Thirty-three COA agreed to participate and granted ethical approval for the research. Half $(n=16)$ was located in the Centre Region of Portugal, and the other half $(n=17)$ was located in the country's North Region. These thirty-three daycare centers were attended by a total of 1638 adults with ID before the first lockdown and a total of 1192 adults at the time the study took place.

A professional of the COA was asked to answer an online survey, namely the professional who knew best the COA, its clients, and families, as well as the COVID-19 impact on each of them. If more than one professional of the COA met these criteria, then the survey could be answered independently by more than one professional. A total of thirty-five professionals answered the survey, three from the same COA and all the others from different COA. They were mainly female $(n=27,77.1 \%)$, aged between 26 and $65(M=$ 43.52, $D P=8.33)$, hold at least a degree level $(n=24$, $68.6 \%)$ and were predominantly technical directors $(n=$
$17,48,5 \%)$ or coordinators of the COA $(n=5,14,3 \%)$. Other professions were also represented (e.g., psychologist, social worker).

\section{Procedure}

The anonymous online survey was presented through the Google Forms platform. When accessing the link, participants found information about the study's goals, the method, the professionals who could answer the survey, a guarantee of anonymity, and a statement of informed consent. All respondents had to give their consent before being directed to the survey questions. Thus, and following the principles of the Declaration of Helsinki, informed consent was included in the survey.

Responses were stored only when the participants clicked the submission button at the end of the survey. They could also stop their participation at any time.

\section{Survey}

The survey included 8 sections, but only 6 will be addressed in this paper. These sections are: section 1) demographics (5 questions regarding the participants and the $\mathrm{COA}$ ); section 2) the number of clients before and after the first lockdown and number of months the COA has been closed (4 questions); section 3 ) impact of the pandemic on several life domains of adults with ID [2 questions, one of them with 10 items scored with a 4 points rating scale: none (0), mild (1), moderate (2) and serious (3)]; section 4) impact of the pandemic in families (2 questions, one of them with 6 items scored with the just mentioned 4 points rating scale); section 5 ) adherence to preventive measures by the adults with ID [1 question with 12 items scored according to a 4 points rating scale: very easy (1), easy (2), difficult (3) and very difficult (4)]; section 6) consequences of the health authorities' guidelines on the COA activities [1 question with 7 items scored according to a 5 points rating scale from Totally disagree (1) to Totally Agree (5)].

The questions with items demonstrated adequate internal consistency, namely the question of section 3 (Cronbach's alpha $=.87$ ), the question of section 4 (Cronbach's alpha $=.73$ ), the question of section 5 (Cronbach's alpha $=.87$ ) and the question of section 6 (Cronbach's alpha $=.77$ ).

Sections 3 and 4 addressed several domains according to the recognition that well-being is multidimensional and in line with the possibility that 
COVID-19 impact might be broad, particularly in vulnerable populations [11, 12].

\section{Statistical Analyses}

Statistical analyses were performed using SPSS 22.0. Descriptive statistics were used to address the aims of this paper. The internal consistency of the questions of the survey with items was analyzed with Cronbach's alpha.

\section{RESULTS}

\section{Attendance before and after the Lockdown}

The number of clients who attended the COA before the lockdown was between 12 and 120 , with a mean value of $46.80(S D=22.17)$ and a median of 47 . The COA were closed for approximately two and half months $(M=2.39$; $S D=0.91)$. After the lockdown, and when the survey took place (between the $15^{\text {th }}$ of September 2020 and the $15^{\text {th }}$ of October 2020), the COA were attended by a mean of 34 clients $(M=$ 34.06; $S D=15.57$ ) and a median of 35. Therefore, there was a decrease in the number of clients, and the mean percentage of clients at that time as $73.18 \%$ (SD $=19.14)$.

\section{Impact on Adults with ID and Families}

The participants considered that the pandemic had a negative impact on the adults with ID. However, when asked to indicate the percentage of adults where that had happened, the values were diverse: 7 participants indicated $5 \%$ and $10 \% ; 15$ participants answered percentages between $17 \%$ and $40 \%$; 13 participants indicated percentages between $50 \%$ and $100 \%$. The mean percentage was $39.40 \%$ ( $S D=$ 25.93). Table 1 shows the impact in several life domains of the adults with ID. It occurred in all domains and mainly in daily occupation, mental health, interpersonal relationships, mobility, and family life, which obtained a mean value superior to 1.5 (moderate impact). However, physical health, self-care, and cognitive functioning obtained values between 1 and 1.5 , indicating a mild impact.

Regarding the impact in the families, the results were similar to the above mentioned: the majority of the participants $(n=32)$ considered that the pandemic had a negative impact on the families; but the percentages of families where that happened were situated between $3 \%$ and $10 \%$ (3 participants); $17 \%$ and $40 \%$ (13 participants); and $50 \%$ and $100 \%$ (16 participants). Overall, the mean percentage was $38.75 \%$ ( $S D=$ 26.44). According to Table 1, the impact was mainly in mental health, relationships with the person with ID, and interpersonal relationships.

\section{Adherence to Preventive Measures}

Table 2 indicates that only three preventive measures were considered easy to apply by adults with ID: to use alcohol gel hand sanitizer, to allow other people to wear a mask, and to wear a protective gown over the clothes. All the other measures had some degree of difficulty associated, which was more evident in:

Table 1: Impact on Adults with ID and Families

\begin{tabular}{|c|c|c|c|c|}
\hline & \multicolumn{2}{|c|}{ Adults with ID } & \multicolumn{2}{|c|}{ Families } \\
\hline & $M$ & $S D$ & $M$ & $S D$ \\
\hline 1. Physical Health & 1.20 & 0.80 & 1.12 & 0.65 \\
\hline 2. Mobility & 1.60 & 0.74 & --- & --- \\
\hline 3. Mental Health & 1.69 & 0.72 & 1.85 & 0.76 \\
\hline 4. Feeding Independently & 0.66 & 0.73 & --- & --- \\
\hline 5. Self-care & 1.37 & 0.77 & --- & --- \\
\hline 6. Cognitive Functioning & 1.37 & 0.69 & 0.82 & 0.64 \\
\hline 7. Interpersonal Relationships & 1.66 & 0.77 & 1.42 & 0.66 \\
\hline 8. Daily Occupation & 2.06 & 0.77 & --- & --- \\
\hline 9. Material Well-being & 0.97 & 0.75 & 1.18 & 0.89 \\
\hline 10. Family Life & 1.57 & 0.70 & --- & --- \\
\hline 11. Relationship with person ID & --- & --- & 1.42 & 0.66 \\
\hline Total & 14.14 & 5.01 & 8.06 & 2.68 \\
\hline
\end{tabular}


Table 2: Adherence to Preventive Measures by Adults with ID

\begin{tabular}{|l|l|l|}
\hline & $M$ & $S D$ \\
\hline \hline 1. Distance of 2 meters & 3.11 & 0.72 \\
\hline 2. Frequent handwash & 2.29 & 0.71 \\
\hline 3. To wear a mask & 2.66 & 0.87 \\
\hline 4. To use alcohol gel hand sanitizer & 2.03 & 0.62 \\
\hline 5. To cough or sneeze into the elbow & 3.11 & 0.76 \\
\hline 6. To suppress hugs, kisses, and handshaking & 3.00 & 0.69 \\
\hline 7. To wear mask properly & 3.20 & 0.68 \\
\hline 8. To avoid touching face... & 3.43 & 0.56 \\
\hline 9. Allowing other people to wear a mask & 1.77 & 0.60 \\
\hline 10. To wear a gown over the clothes & 1.60 & 0.55 \\
\hline 11. To avoid sharing objects & 2.77 \\
\hline 12. Isolation & 3.29 & 0.88 \\
\hline
\end{tabular}

- to avoid touching face, eyes, or mouth when hands were not clean;

- $\quad$ being in isolation;

- $\quad$ to wear mask properly;

- $\quad$ to cough or sneeze into the elbow;

- $\quad$ to keep a two meters distance; and

- $\quad$ to suppress hugs, kisses, and handshaking.

\section{Consequences of the Health Authorities' Guidelines in the COA Activities}

As Table 3 shows, the participants agreed that the health authorities' guidelines influenced the activities performed in the COA: there were not only less activities but also less diversified, more sedentary, and more indoor activities. The items related to less stimulating activities and the extinction of small groups activities obtained moderate agreement.

\section{DISCUSSION}

The survey took place after the first lockdown in Portugal, in September and October of 2020, when the COA were again in functioning. Nevertheless, they were attended by only $73.18 \%$ of the clients, which means that the remaining $26.82 \%$ stayed at home or at group homes. This can be due to fear of contagion, transport regulations that limited the number of users (both in public transports and COA vans and buses) and made it much more difficult to go to the COA, or difficulties of the COA themselves (e.g., in terms of less space available, less personnel, constant cleaning...). Whatever the reasons, the fact is that some adults with ID remained restricted to their homes and therefore extended their hard-living conditions over a long period. Since a second lockdown occurred between January and March of 2021, it is admissible that the confinement may have lasted a year for some adults with ID in Portugal. And the picture may be even worse when one considers the possibility that the contact with

Table 3: Consequences of the Health Authorities' Guidelines on the Activities

\begin{tabular}{|c|c|c|}
\hline & $M$ & $S D$ \\
\hline 1. Less varied activities & 3.71 & 1.02 \\
\hline 2. Reduction of activities & 3.80 & 0.96 \\
\hline 3. Extinction of outside activities & 3.46 & 1.25 \\
\hline 4. Choice of more sedentary activities & 3.06 & 1.00 \\
\hline 5. Extinction of sport activities & 2.86 & 1.12 \\
\hline 6. Choice of less stimulating activities & 2.69 & 0.83 \\
\hline 7. Extinction of small group activities & 2.54 & 1.04 \\
\hline
\end{tabular}


services and professionals, including the COA, may have been restricted during that long time period.

Participants agreed that the pandemic had a negative impact on adults with ID, although only in a percentage of them $(39.40 \%)$. This shows that many adults with ID showed resilience during the pandemic, as verified by other researchers in countries such as the Netherlands [13] or Spain [14]. On the other hand, according to the COA professionals, a considerable percentage of the adults with ID showed negative consequences of the pandemic in various life domains and not only in mental health. The main life domains affected include daily occupation, mental health, interpersonal relationships, family life, mobility, physical health, self-care, and cognitive functioning.

A generalized impact of the pandemic has already been shown in other vulnerable populations groups, such as older people [12] and older people with physical disabilities [15]. In adults with ID, this generalized impact can be due to pre-pandemic conditions, the many disruptions introduced by the pandemic into their lives, or an interaction between the two. For instance, adults with ID that attend COA usually have a disability with some severity, may need more support, have more restricted networks or fewer resources (e.g., coping resources, financial...). However, the pandemic and the lockdown brought social isolation and loneliness, the majority or totality of time spent at home, loss of structure and routines, loss of contact with peers, reduced contacts with professionals, difficulty or impossibility in access to services, interruption of rehabilitation activities and therapies and all of these factors increase risks of problems in mental health, interpersonal relationships, mobility, physical health, and cognitive functioning. During the lockdown, the loss of purposeful daily activities and leisure activities performed at the daycare centers may also have seriously impacted the ability to keep a daily occupation and in other life domains, as indicated in this study.

As the results concerning the consequences of the health authorities' guidelines on the COA activities indicated, the performance of meaningful daily activities in the COA was still seriously compromised after the first lockdown when some of the adults with ID returned to the COA. Therefore, the difficulty in keeping themselves busy, a fact that appeared during the lockdown, may have persisted afterward because the COA provided less and more sedentary activities.
The impact of the pandemic in the families mirrors that of the adults with ID: it concerns many, but not all, families $(38.75 \%)$, and it expresses itself in several life domains (mainly mental health, relationships with the person with ID, and interpersonal relationships). Family overload due to providing 24 hours care, exacerbation of ongoing problems and practical difficulties, reduction of access to professional support and services, dilution of social support are all possible causes of the impact $[2,7]$. In addition, family caregivers of adults with ID are, probably, older people, and in a country like Portugal, poor people. This can seriously accentuate the strain.

The difficulties that the adults with ID had implementing preventive measures can result from various reasons. Firstly, they may not fully understand the measures, the severity of the situation, or the consequences of not complying with the rules and measures [1, 8, 9]. Secondly, the information they receive may not be sufficiently clear. Although easy-toread materials about COVID-19 and preventive measures have been designed by several Portuguese entities, there is no evidence that these materials are effectively easy to read and comprehend. Moreover, as adults with ID may have few or no literacy skills, we do not know any oral materials that have been developed in a way that can effectively facilitate understanding. Thirdly, adults with ID may have specific challenges, such as hand dexterity and fine motor difficulties, that compromise the adoption of preventive measures (e.g., to wear a mask). Fourthly, the support provided by caregivers to some adults with ID may also imply physical assistance and proximity (e.g., help in selfcare activities), thus contradicting norms such as social distance. Fifthly, the cultural context may also have had influence, since in Portugal before the pandemic, the physical proximity was usual, and people greeted each other regularly with kisses.

This study has limitations: it is just descriptive, has a small sample, the participants did not include the adults with ID or their families, and it relates to a very specific time period. The fact that the participants were only COA professionals results from the practical impossibility of contacting directly or through digital methods of communication the adults and families (inaccessible to many).

\section{CONCLUSIONS}

Without prejudice to the previous considerations, this study is the only available concerning COVID-19 
and Portuguese adults with ID to the best of our knowledge. Its results clearly show the profound impact of the pandemic after the first lockdown, which can be even much more intense now, after a second lockdown and more than one year living in such adverse conditions. As it might have happened with other minority groups, people with disabilities were left behind during the pandemic, and so the time has come: to provide more rehabilitation services to the adults in order to try to reverse the negative consequences; to offer more supports to the families including respite care; to prepare and assess clear information regarding health crises and preventive measures.

\section{ACKNOWLEDGEMENTS}

We gratefully acknowledge all the participants in this study.

\section{DISCLOSURE STATEMENT}

The author reports no declaration of interest.

\section{REFERENCES}

[1] Alexander R, Ravi A, Barclay H, Sawhney I, Chester V, Malcolm V, Brolly K, Mukherji K, Howell A, Lane T, Cooper V, Langdon $\mathrm{P}$. Guidance for the treatment and management of COVID-19 among people with Intellectual Disabilities. J Policy Practice Intellect Disabil 2020; 17(3): 256-269. https://doi.org/10.1111/jppi.12352

[2] Courtenay K, Perera B. COVID-19 and people with intellectual disability: Impacts of a pandemic. Ir J Psych Med 2020; 37(3): 231-236 https://doi.org/10.1017/ipm.2020.45

[3] Hughes N, Anderson, G. The experience of the COVID-19 pandemic in a UK learning disability service: lost in a sea of ever-changing variables - a perspective. Int J Dev Disabil 2020.

https://doi.org/10.1080/20473869.2020.1773711

[4] Rosencrans $M$, Arango $P$, Sabat $C$, Buck $A$, Brown $C$, Tenorio M, Witwer A. The impact of the COVID-19 pandemic on the health, wellbeing, and access to services of people with Intellectual and Developmental Disabilities. Res Dev Disabil 2021; 114

https://doi.org/10.1016/j.ridd.2021.103985
[5] Theis N, Campbell N, De Leeuw J, Owen M, Schenke KC. The effects of COVID-19 restrictions on physical activity and mental health of children and young adults with physical and/or intellectual disabilities. Disabil Health J 2021. https://doi.org/10.1016/j.dhjo.2021.101064

[6] Rose J, Willner P, Cooper V, Langdon PE, Murphy GH, Kroese, BS. The effect on and experience of families with a member who has Intellectual and Developmental Disabilities of the COVID-19 pandemic in the UK: developing an investigation. Int J Dev Disabil 2020. https://doi.org/10.1080/20473869.2020.1764257

[7] Willner $P$, Rose J, Stenfert Kroese B, Murphy GH, Langdom PE, Clifford C, Hutchings H, Watkins A, Hiles S, Cooper V. Effect of the COVID-19 pandemic on the mental health of carers of people with intellectual disabilities. J Appl Res Intellect Disabil 2020; 33: 1523-1533. https://doi.org/10.1111/jar.12811

[8] Embregts PJ, van den Bogaard KJ, Frielink N, Voermans MA, Thalen M, Jahoda A. A thematic analysis into the experiences of people with a mild intellectual disability during the COVID-19 lockdown period. Int J Dev Disabil 2020. https://doi.org/10.1080/20473869.2020.1827214

[9] Embregts PJCM, Tournier T, Frielink N. Experiences and needs of direct support staff working with people with intellectual disabilities during the COVID-19 pandemic: A thematic analysis. J Appl Res Intellect Disabil 2021; 34: 480490.

https://doi.org/10.1111/jar.12812

[10] Portaria n. ${ }^{\circ} 70 / 2021$ de 26 de Março de 2021, Diário da República, $1^{\mathrm{a}}$ série, $\quad 60,23-40$. Available at https://data.dre.pt/eli/port/70/2021/03/26/p/dre

[11] Brooke J, Jackson D. Older people, and COVID-19: Isolation, risk, and ageism. J Clin Nurs 2020; 29: 2044-2046. https://doi.org/10.1111/jocn.15274

[12] De Pue S, Gillebert C, Dierckx E, Vanderhasselt M-A, De Raedt R, Van den Bussche E. The impact of the COVID-19 pandemic on wellbeing and cognitive functioning of older adults. Sci Rep 2021; 11. https://doi.org/10.1038/s41598-021-84127-7

[13] Scheffers F, Moonen X, van Vugt E. Assessing the quality of support and discovering sources of resilience during COVID19 measures in people with intellectual disabilities by professional carers. Res Dev Disabil 2021; 111. https://doi.org/10.1016/j.ridd.2021.103889

[14] Navas P, Amor AM, Crespo M, Wolowiec Z, Verdugo MA Supports for people with intellectual and developmental disabilities during the COVID-19 pandemic from their own perspective. Res Dev Disabil 2021; 108. https://doi.org/10.1016/j.ridd.2021.103813

[15] Steptoe A, Di Gessa, G. Mental health and social interactions of older people with physical disabilities in England during the COVID-19 pandemic: a longitudinal cohort study. Lancet Public Health 2021; 6(6). https://doi.org/10.1016/S2468-2667(21)00069-4

\section{https://doi.org/10.6000/2292-2598.2021.09.05.15}

(c) 2021 Cristina P. Albuquerque; Licensee Lifescience Global.

This is an open access article licensed under the terms of the Creative Commons Attribution Non-Commercial License (http://creativecommons.org/licenses/by-nc/3.0/) which permits unrestricted, non-commercial use, distribution and reproduction in any medium, provided the work is properly cited. 